\title{
The International Communication Strategy of Root Culture Under the Background of New Media
}

\author{
Yaqiong Liu* \\ School of Journalism and Communication, Henan University of Technology, China \\ *Corresponding author. Email: liu381052@163.com
}

\begin{abstract}
Culture is a social phenomenon and the product of people's long-term practice. At the same time, it is a kind of historical phenomenon. In recent years, the practice activities of Hong Kong, Macao and Taiwan compatriots from the Central Plains and overseas Chinese who have returned to the Central Plains to "seeking their roots" have attracted extensive attention from Chinese at home and abroad. In addition, these activities also provide an opportunity for Root Culture to spread to the world. However, some problems have emerged in the process of dissemination, such as the weakening of cultural communication power by cultural estrangement, the lack of in-depth excavation of the connotation of Root Culture and the single communication channel. In the face of these problems, it is necessary to change the strategy of international communication of Root Culture in the new media environment. Communicators should pay attention to the cultural estrangement in cultural communication and deeply explore Root Culture in the Central Plains. Furthermore, create a diversified publicity environment and broaden the international communication channels of Root Culture with the help of new media platform.
\end{abstract}

Keywords: Root Culture, International Communication, Strategy.

\section{INTRODUCTION}

Root Culture in Central Plains is a cultural term with geographical characteristics. It is a special cultural phenomenon of humanistic return and selfconsciousness formed by the Central Plains region relying on its own profound cultural heritage through historical evolution.Mainly manifested as the practice activities of Hong Kong, Macao and Taiwan compatriots from the Central Plains and overseas Chinese returning to the Central Plains to seeking their roots. With this kind of "root-seeking" practical activities, the Central Plains region will hold Root-Kin cultural activities with the theme of "Root-Kin" every year, such as the worship ceremony of the humanistic ancestor The Yellow Emperor Xuanyuan in Xinzheng, Henan and the "Root-Kin cultural festival" in the Gushi area of Central Plains. Through the ancestor worship ceremony and cultural festivals, many Chinese children from home and abroad were attracted to gather in the Central Plains. At the same time, with the help of these cultural activities, it also spreads the unique Root Culture to the world.

\section{OVERVIEW OF ROOT CULTURE}

\subsection{Central Plains Cultural Connotation}

"Central Plains" is a noun that represents regionality. In Cihai, "Central Plains" is annotated from two aspects in a narrow sense and a broad sense. In the narrow sense, the Central Plains refers to the current Henan region; in a broad sense, the Central Plains refers to the middle and lower reaches of the Yellow River or the entire Yellow River basin. The contemporary understanding of the Central Plains tends to be unified, that is, Henan Province is the center of the geographic region and a small part of the surrounding area affected by its traditional culture. The Central Plains Culture is a culture created by the people living in the Central Plains during the long history of social and historical development. Because of the unique regional characteristics and natural environment in the middle and lower reaches of the Yellow River, as early as two thousand years BC, the emperors of the Xia Dynasty regarded the Central Plains as a political, economic and cultural center.The establishment of dynasties, the invention of characters and the formation of cities gave 
birth to the embryonic form of the Central Plains Culture. With the evolution and development of history, more than 20 dynasties have set their capitals in the ancient Central Plains with Henan as the center. Because of the change of dynasties, the migration of population and the deep integration of religious culture, a broad, profound and unique Central Plains Culture has gradually formed, including Shangdu Culture, Songshan Culture, Huangdi Culture, Yellow River Culture, Root Culture, Martial Arts Culture, etc. Cultural heritage is mainly divided into two aspects, namely material culture and intangible culture. Material culture mainly includes historical books, historic buildings, ground and underground cultures and ruins, etc.; intangible culture mainly includes ideological and academic, value orientation, customs and habits, etc.

\subsection{Root Cultural Connotation}

From a theoretical perspective, Root Culture is interpreted as a social and cultural activity with the "seeking root" practice as the main body.It uses the excellent traditional culture of the Central Plains as the nourishment of the mother's inheritance and innovation of excellent traditional culture.Its main practical manifestation is the practice activities of overseas Chinese and compatriots from Hong Kong, Macao and Taiwan to search for their roots and ancestors in the central Plains. In terms of content, it mainly includes two aspects. First, Root culture has always been bred and grown with the excellent Central Plains Culture. With the long history of the Central Plains Culture, the Central Plains roots are rich in cultural resources; secondly, the current "root seeking" practice activities are in full swing. It is the most dynamic form of expression of Root Culture.

The rich resources of Root Culture in Central Plains are mainly reflected in the fact that Root Culture is nurtured by Central Plains Culture, so it is deeply influenced by excellent Central Plains Culture in content. As we know, such as the cultural resources of family names, historical celebrities, political culture, written culture and religious culture are the most representative resources of Root Culture.

There are two main forms of expression of Root Culture. The first is the root-seeking activities of compatriots in Hong Kong, Macao and Taiwan and overseas Chinese. The second type is root cultural activities in the Mainland China. In 1982, Diancheng Huang, a Hong Kong scholar, went on a root-seeking trip in Central China, which became the most representative starting point for Hong Kong, Macao and Taiwan compatriots as well as overseas Chinese to seek their roots in Central China. Since 1999, Overseas Exchange Association of the Overseas Chinese Affairs Office of the State Council of China has held a summer camp with the theme of "China's Root-seeking Trip" every few years. It has attracted enthusiastic participation of young people from all over the world, including Hong Kong, Macao and Taiwan, to experience the development of China, their ancestral land, and feel the charm of traditional culture flowing in their genetic blood. In the Central Plains, various root Pro cultural activities have also been carried out rapidly. The ancestor worship ceremony in the hometown of the Yellow Emperor in Xinzheng, Henan Province and the "Root Culture festival" in Gushi have become representative Root Culture activities in the Central Plains. The annual Root Culture activities in central Plains are not only cultural events in Central Plains, but also attract thousands of Chinese children who travel thousands of miles to get together in Central Plains to feel the profoundness and solemnity of Central Plains Culture.

\section{INTERNATIONAL COMMUNICATION STATUS OF ROOT CULTURE}

\subsection{Root-seeking Activities Improve the International Influence of Root Culture}

Nowadays, the rise of Root Culture and related cultural construction in the Central Plains are closely related to the practice of "root-seeking" by overseas returnees. More and more overseas returnees come to the Central Plains to continue their kinship, geography, blood relationship and cultural ties. They have become an important bridge between the Central Plains and overseas. What they see, hear and feel in their ancestral home in central China has played a huge role in promoting the spread and popularity of excellent Traditional Chinese Culture. They are the best interpreters of the "Chinese story". In the hometown of the Yellow Emperor worship ancestors ceremony of the activities in the Central Plains and so on many cultural exchange activities not only let overseas Chinese feel Root Culture, but also promoted the international influence of Root Culture.

\subsection{Cultural Barriers Weaken Root Culture Dissemination}

Root Culture wants to go to the world and increase its international influence. If the target of dissemination is limited to the group of overseas Chinese, then the influence will be very limited. If government want to expand international popularity and influence, they should tell the "Chinese story" with the people of all countries and nations around the world as the target of dissemination. However, the broad, profound and rich connotation of Root Culture needs to be further understood and integrated on the basis of a certain accumulation of the Central Plains Culture. For foreign friends, although overseas Chinese play a supporting role in the communication process, if they have not 
accumulated relevant cultural knowledge before, it is difficult for them to understand why overseas Chinese who were born and grew up overseas still have to go back to their hometown to find their roots. This situation will inevitably lead to obstacles and estrangement in the process of cultural exchange. The low understanding of information by the information receiver will weaken the communication power of Root Culture. The cultural estrangement between the two sides is a very important problem faced by Root Culture in the process of international communication.

\subsection{Root Culture Connotation Is Not Fully Explored}

Root Culture is nurtured by the Central Plains Culture. It is deeply influenced by the excellent Central Plains Culture in content. It is rich in cultural resources, mainly including surname cultural resources, historical celebrity cultural resources, political cultural resources, written cultural resources religious cultural resources. However, after analyzing the current international communication activities of Root Culture, it is found that the content mining and external communication of Root Culture in Henan Province stay on the surname culture, and the root seeking culture in the Central Plains is also dominated by the surname root seeking culture. The "Root Culture" festival, ancestor worship ceremony and relevant surname celebrity commemoration activities are the main practice forms of Root Culture in the Central Plains. In contract, historical celebrity culture, folk culture, religious culture and other carriers that can more comprehensively display Root Culture of the Central Plains have not been widely known. These are also important components of the Central Plains Culture, but they have not been fully explored and sorted out, which can easily lead to foreigners having little knowledge and deep impression of Root Culture in international communication.The communication effect is greatly reduced.

\subsection{Root Culture Dissemination Channels and Means Are Single}

At present, the communication channels Central Plains Culture are still dominated by traditional official channels, supplemented by the communication activities of non-governmental spontaneous organizations.The communication mode and form are single. The traditional media, such as newspapers and television, still report the root seeking activities of overseas Chinese, which is the main way for the external communication of Root Culture. Although the interpersonal communication of overseas Chinese to foreign friends abroad can achieve better communication results, its influence is still very small.Some communication channels and means with wide communication effects have not been fully utilized.

In the new media era, the media's news reports and information dissemination can integrate various media forms and target the different needs of different audiences through various channels and platforms for comprehensive and multi-level integrated dissemination. The application and popularization of social media can be to maximize the spread of Root Culture.The new medium is a substitute for the traditional media, and it is also an opportunity for the development of Root Culture. At present, there is only one Root Culture website for publishing news information. There is no more professional Root Culture portal site to introduce the long historical and cultural resources of the Central Plains in detail. At the same time, it did not use today's global popular social platforms, such as ins, YouTube, TikTok, Facebook, and Twitter to actively push content related Root Culture. Only the personal social accounts of overseas Chinese will publish their own root-seeking activities disseminate the innovative achievements of contemporary Chinese culture. These dissemination activities are not assisted by official accounts, and few people follow them.

\section{THE INTERNATIONAL COMMUNICATION STRATEGY OF ROOT CULTURE UNDER THE BACKGROUND OF NEW MEDIA}

Root Culture has continued to flourish along with the great root-seeking activities of overseas Chinese. However, Root Culture has encountered many problems in the process of international communication, such as the weakening of the communication power of Root Culture by cultural estrangement and the single communication channels. Communicators need to change their communication strategies in the new media environment, pay attention to the cultural barriers in cultural communication, and spread Root Culture by telling stories. At the same time, Communicators should deeply explore Root Culture. Finally, in terms of communication channels, Communicators should create a diversified and activated publicity environment and broaden the international communication channels of Root Culture.

\subsection{Attach Importance to Cultural Differences in Cultural Communication}

The dissemination of culture will be greatly restricted in the cross-cultural process. The greater the cultural difference, the greater the difficulty of cultural dissemination. Therefore, in the international dissemination of Root Culture, it is necessary to pay attention to the cultural differences between China and foreign countries. In order to overcome cultural 
differences, a very important means is to tell the story of Root Culture. In the report of the 19th National Congress of the Communist Party of China, president of the People's Republic of China Jinping Xi proposed that "We must strengthen cultural exchanges between China and foreign countries, promote the development of international communication capabilities, tell Chinese stories well, show a comprehensive China, and improve the country's cultural soft power. "The Central Plains story, which includes Root Culture, is an integral part of the Chinese story. Telling the Central Plains story well, publicizing the Central Plains Culture, and innovating the discourse system is an important means to do a good job in the international communication of Root Culture, and enhance the international influence of Root Culture.

\subsection{Deeply Tap Root Culture to Lay the Foundation for International Communication}

The formation of Root Culture is deeply influenced by Central Plains Culture, and its connotation is very rich. To make Root Culture better spread to the world, it is necessary to dig deep into the connotation of Root Culture, which is the foundation of international communication. Therefore, the promotion of Root Culture should not only stop at the root culture festival, ancestor worship ceremony and related surname celebrity commemorative activities jointly organized by overseas Chinese and the government, but must dig deeper into the historical origin of Root Culture. The clan culture formed under the patriarchal clan system and blood relationship system is an important part of Root Culture. This culture, which is closely related to historical changes, development of the times, and social changes, is not only a family culture, but also a traditional concept that values family ethics and inheritance. If these deep cultural connotations are not explored, then the international communication of Root Culture will only stay on the surface without touching the core. This will cause foreign audiences to receive simple information and cannot understand what the spiritual core of the Central Plains culture is.

\subsection{Broaden the International Communication Channels of Root Culture with the Help of New Media Platform}

Cultural communication under the new media environment is not completely separated from traditional media, but allows new media and traditional media resources to be shared to achieve complementary advantages. First of all, in the current new and active cultural propaganda environment of new media, mainstream media, commercial media and self-media can be used to increase the propaganda of Root Culture. For example, various TV stations and self-media create more traditional cultural programs and the programs are forwarded to foreign websites for dissemination.
Secondly, innovate the form and content of traditional media. For example, set up a column on the root culture of the Central Plains, and integrate the traditional history and culture into the story. Whether it is the official media or self-media, it can also use the "Internet plus" environment to build its own social media account on YouTube, TikTok and Facebook, and publicize the rich culture of the Central Plains, creating an international influence media account. Finally, integrate excellent traditional culture into literature, art, film and television works, such as making micro interviews with root seeking characters to tell their own root seeking stories, shooting videos of root seeking activities of overseas Chinese and documentaries about Root Culture for overseas dissemination. These activities can promote the popularization and globalization of excellent Root Culture. At the same time, communicators will give play to the role of government organizations, build communication bridges, and seize the opportunity of the "Belt and Road". In the world-wide international exhibitions, government can negotiate with other countries to open a foreign trade e-commerce service trading platform for publishing, audiovisual and digital media products. Cultural products related to Root Culture build a convenient bridge for sales overseas and promote the international spread of Root Culture.

\section{ACKNOWLEDGMENT}

This paper was funded by "Media Ecology and Social Governance Innovation Research Center" Key Research Base of Humanities and Social Sciences (Cultivation) of Henan Province Colleges and Universities.

\section{REFERENCES}

[1] Baogui Li, Hui Li, The connotation, elements and improvement strategies of Chinese international communication ability $[\mathrm{J}]$. Application of Language and Writing, 2021(02): 2-15. DOI: 10.16499/j.cnki.1003-5397.2021.02.001

[2] Quanming Zhou,The morphological characteristics and functional effects of the root culture of the Central Plains in the new era[J].Journal of Zhoukou Normal University,2015,32(01):92-95. DOI: 10.13450/j.cnki.jzknu.2015.01.024

[3] Jia Sun, Research on the International Communication of Traditional Sports under the Background of "One Belt One Road"[J].Journal of Beijing Institute of Graphic Communication, 2021, 29(04):22-24+34. DOI: 10.19461/j.cnki.10048626.2021.04.007

[4] Yang Yu, Fei Jiang, New characteristics and new trends of international cross-cultural communication research $[\mathrm{J}]$. International 
Journalism, 2021, 43(01): 67-84.

DOI: 10.19293/j.cnki.1673-8357.2017.01.004

[5] Yonghua Zhao,Juan Zhao,Choice of "One Belt One Road" Cross-cultural Communication Path from the Perspective of Cultural Identity[J].International News,2018,40(12):67-82.

DOI: 10.13495/j.cnki.cjjc.2018.12.005

[6] Xiaofei Hu, Yiqing Hu, Breakthrough, Integration and Innovation: The Status Quo and Prospect of "Telling Chinese Stories" Research [J].Media Observation, 2021(09):5-16. 10.19480/j.cnki.cmgc.2021.09.005

DOI:
[7] Xinbin Zhang, Discussion and thinking on root culture [J]. Central Plains Cultural Studies, 2014, 2(03): 103-108.

DOI: 